\title{
Differences in health-promoting properties in civilisation diseases of Agaricus bisporus fruiting bodies harvested from three flushes
}

\author{
Anna Wlodarczyk', Agata Krakowska ${ }^{2}$, Jan Lazur ${ }^{1, *}$, \\ Katarzyna Sulkowska-Ziaja ${ }^{1}$ Bożena Muszyńska ${ }^{1}$

\begin{abstract}
${ }^{1}$ Department of Pharmaceutical Botany, Faculty of Pharmacy, Jagiellonian University Medical College, 9 Medyczna Street, 30-688 Kraków, Poland

${ }^{2}$ Department of Inorganic and Analytical Chemistry, Faculty of Pharmacy, Jagiellonian University Medical College, 9 Medyczna Street, 30-688 Kraków, Poland
\end{abstract}

\begin{abstract}
A controlled environment and composition of the compost used for the commercial production of Agaricus bisporus can allow fruiting bodies with increased nutritional value to be obtained. The present study aimed first to investigate the content of bioelements in fruiting bodies of $A$. bisporus harvested from three flushes of cultivation and to estimate which elements are accumulated most effectively by determination of bioconcentration factor (BCF). The second aim of the study is to determine the amount of selected organic compounds in the A. bisporus fruiting bodies harvested from three flushes of cultivation and to evaluate their antioxidant activity. Among the three examined A. bisporus flushes, the first is considered the most valuable, since it was rich in dietary and nutritional substances, and has shown promise of antioxidant and antidepressant activities. The present study is the first to describe a complex evaluation of the content of bioactive substances and antioxidant activity in three different cultivation flushes of $A$. bisporus fruiting bodies.
\end{abstract}

Keywords: antioxidant activity, cultivation, ergothioneine, 5-hydroxy-L-tryptophan, lovastatin

Abbreviations: AAS, atomic absorption spectrometry; BCF, bioconcentration factor; DPPH, 1,1-diphenyl-2picrylhydrazyl; HPLC, high-performance liquid chromatography; RP-HPLC, reversed-phase high-performance liquid chromatography; 5-HTP, 5-hydroxy-L-tryptophan.

\section{INTRODUCTION}

Agaricus bisporus (JE Lange) Imbach (white mushroom) of the family Agaricaceae is now cultivated in at least 70 countries around the world. Commercial breeding of A. bisporus was first achieved by the French botanist Joseph Pitton de Tournefort in 1707 (Spencer, 1985). Since this mushroom species was originally cultivated in Paris, it was designated with the French common name champignon de Paris (Spencer, 1985). Olivier de
Serres, another French farmer, found that transplanting mushroom mycelium into a new medium leads to an increase in the number of fruiting bodies. However, the resulting crops were often infected and were not conducive for good fruiting development. Pure mycelial cultures of $A$. bisporus grown on horse manure were obtained in 1893 at the Pasteur Institute in Paris. The originally obtained fruiting bodies were brown in

*Corresponding author.

e-mail: janlazur@gmail.com (Jan Lazur). 
colour, but in 1926, a white fruiting body was obtained in Pennsylvania, which became much more popular with consumers.

Commercial cultivation of $A$. bisporus is carried out in compost which is composed of lignocellulosic material that is a source of carbon and essential nutrients for mushroom growth (Zhang et al., 2020). The compost may be prepared from fermented wheat straw, horse and/or chicken manure, and gypsum (Jurak et al., 2015).

The most important features of $A$. bisporus are its dietary and therapeutic properties resulting from the rich composition of primary and secondary metabolites, from which the biologically active substances profitable for animal and human health can be distinguished (Muszyńska et al., 2016). A. bisporus is a rich source of dietary fibre (chitin); exo- and endogenous amino acids; unsaturated fatty acids, including palmitic, linoleic, and linolenic acids; vitamins; and easily digestible protein and antioxidant compounds such as sterols and phenolic and indole compounds. The antioxidant and antidepressant activities of $A$. bisporus are also associated with the presence of the histidine derivative ergothioneine (Muszyńska et. al., 2017). Besides antioxidant activity of ergothioneine, it also exhibits antimutagenic and chemoand radioprotective effects. For this reason, it is considered as a valuable substance in medicine (Dubost et al., 2007). This species is also a source of the antiatherosclerosis compound lovastatin and 5-hydroxy-L-tryptophan (5HTP) that shows antidepressant activity (Muszyńska et al., 2015a, 2015b). In addition, these substances also show antioxidant and anti-inflammatory effects (Muszyńska et al., 2018). The compound ergosterol found in the order Agaricales also shows anticancer effects. It exhibits anticancer activity by inhibiting metaplastic cell migration and proliferation. Additionally, the substance may inhibit the growth of new vessels (prevents angiogenesis). In patients treated with ergosterol, tumour growth was delayed, and minimal side effects were observed. In patients receiving chemotherapy, ergosterolrich extracts did not cause any adverse effects on the lymphocytes level (Novaes et al., 2011). A. bisporus can be used for anticancer therapy as it is easily available and inexpensive (Chen et al., 2006). This species also shows neuroprotective activity and could be used for prophylaxis of neurodegenerative diseases (Rai et al., 2021).

The present study firstly aimed to investigate the content of bioelements like zinc, magnesium, iron, copper, calcium, sodium and potassium in the fruiting bodies of $A$. bisporus harvested from three cultivation flushes - after 2 , 3 , and 4 weeks of cultivation on compost and to determine the elements that were accumulated most effectively by determination of bioconcentration factor $(\mathrm{BCF})$.

\section{MATERIALS AND METHODS}

\section{Mushroom materials}

Samples of $A$. bisporus were obtained from three flushes - after 2, 3 and 4 weeks of cultivation from the surface layer of fruiting bodies from a typical commercial cultivation plot in Poland. To prepare samples of A. bisporus cultivation substrate (before inoculation by $A$. bisporus mycelium) for bioelements analysis six ones from area of $50 \mathrm{~cm}^{2}$ and depth of up to $25 \mathrm{~cm}$ were obtained. The A. bisporus samples were deposited in the Department of Pharmaceutical Botany, Faculty of Pharmacy, Jagiellonian University Medical College.

\section{Reagents}

The following reagents with proper purity for mineralisation of the lyophilised biomass and fruiting bodies were used: $30 \% \mathrm{H}_{2} \mathrm{O}_{2} \quad$ Suprapur $^{\circledR}$ and $65 \%$ $\mathrm{HNO}_{3}$ (Merck, Darmstadt, Germany). HLP apparatus (Hydrolab, Poland) was used to obtain quadrupledistilled water with conductivity below $1 \mu \mathrm{S} \cdot \mathrm{cm}^{-1}$. Standards of metals at $1 \mathrm{~g} \cdot \mathrm{L}^{-1}$ were purchased from the District Measurements Office (Łódź, Poland). The standard compound of L-phenylalanine and phenolic compounds were purchased from Sigma-Aldrich (St. Louis, MO, USA). Analytical grade acetic acid, methanol and ammonium acetate were obtained from Chempur (Gliwice, Poland). High-performance liquid chromatography (HPLC) purity methanol was purchased from Honeywell Riedel-de Haën (Seelze, Germany).

\section{Analysis of bioelements}

The A. bisporus fruiting bodies and cultivation substrates from the three flushes ( $3 \mathrm{~g})$ were subjected to wet mineralisation in a closed system in a Magnum device (ERTEC II) by using $6 \mathrm{~mL}$ of concentrated $65 \%$ $\mathrm{HNO}_{3}(\mathrm{~V})$ and $2 \mathrm{~mL}$ of $30 \% \mathrm{H}_{2} \mathrm{O}_{2}$ solution. Samples were analytically transferred to Teflon vessels and mineralised according to the procedure reported previously (Włodarczyk et al., 2020). Atomic absorption spectrometry (AAS, spectrometer - iCE 3500, Thermo Fisher Scientific, Waltham, MA, USA) was selected as the method for determination of selected bioelements in the mineralised fruiting bodies. Each analytical sample prepared was tested in triplicate. Results are presented as mean values with standard deviation (SD).

\section{Preparation of extracts for organic compound determination}

Harvested fruiting bodies of A. bisporus were lyophilised and homogenised in mortar. The weight of each sample was $3 \mathrm{~g}$. Extraction of organic compounds was assisted with ultrasounds at $49 \mathrm{kHz}$ (Sonic-2, Polsonic) and by addition of analytical grade methanol to the weighted samples for $30 \mathrm{~min}$. The procedure was repeated three times for each sample. The final volume of the extracted solutions was $300 \mathrm{~mL}$. Obtained extracts were evaporated in crystallisers to dryness. Remaining residue was dissolved in methanol suitable for HPLC analysis and filtered through membrane filters (Millipore Millex ${ }^{\circledR}$ GP $0.22 \mu \mathrm{m}$; Merck, Darmstadt, Germany). Further analyses were performed as described previously (Krakowska et al., 2016). 


\section{Analysis of phenolic compounds and phenylalanine}

The analysis of phenolic compounds and phenylalanine was performed using the reversed-phase HPLC highperformance liquid chromatography (RP-HPLC) method with diode array detection in a Hitachi-Merc HPLC VWR apparatus with the following specifications: an L-2200 autosampler, an L-2130 pump, an RP-18e LiChrospher column ( $4 \mathrm{~mm} \times 250 \mathrm{~mm}, 5 \mu \mathrm{m})$, an L-2350 thermostat and an L-2455 diode detector working in the ultraviolet (UV) wavelength range of 200-400 nm. Solvent A consisting of methanol $/ 0.5 \%$ acetic acid (1:4, $\mathrm{v} / \mathrm{v}$ ) and solvent B consisting of methanol were used as mobile phase components. The gradient was established as follows: 100:0, 0-25 min; 70:30, $35 \mathrm{~min}$; 50:50, $45 \mathrm{~min}$; 0:100, 50-55 min; and 100:0, 57-67 min. The combination of ultraviolet; (UV) spectra and retention time in relation to the standard compounds enabled the identification of phenolic compounds. Quantitative analysis was performed based on a calibration curve with the initial assumption of linearity of the size of the test area under the peak in relation to the concentration of the applied standard. The contents of phenolic compounds and L-phenylalanine determined in the fruiting bodies were expressed as $\mathrm{mg} \cdot 100 \mathrm{~g}^{-1}$ dry weight (d.w.).

\section{Analysis of indole compounds}

The content of indole compounds was determined using the high-performance liquid chromatography; RP-HPLC-UV method. The extracts were dissolved quantitatively in $1.5 \mathrm{~mL}$ of the solvent system (methanol/ water/ammonium acetate, 15:14:1, v/v/v) and separated in a Hitachi high-performance liquid chromatography; (RP-HPLC) device with a ultraviolet; (UV) detector (Merck, Japan) equipped with an L-7100 pump. A Purospher ${ }^{\circledR}$ RP-18e column (4 mm 200 mm, $5 \mu \mathrm{m}$ ) was maintained at $25^{\circ} \mathrm{C}$, while the ultraviolet; (UV) detector was at $\lambda=280 \mathrm{~nm}$. The liquid phase used was a mixture of methanol, water and ammonium acetate $(15: 14: 1, \mathrm{v} / \mathrm{v} / \mathrm{v})$, and the flow rate was set at $1 \mathrm{~mL} \cdot \mathrm{min}^{-1}$. Qualitative and quantitative analyses of indole compounds were carried out analogously to those of phenolic compounds.

\section{Analysis of sterols}

The content of sterols was analysed using the HPLC method according to the protocol described previously with the author adjustments (Yuan et al., 2008; Sułkowska-Ziaja et al., 2018). The mobile phase used for the analysis consisted of solvent A containing methanol and water $(80: 20, \mathrm{v} / \mathrm{v})$ and solvent B containing methanol and dichloromethane $(75: 25, \mathrm{v} / \mathrm{v})$. The gradient programme was as follows: $80: 20$ for $0-10 \mathrm{~min}$; 40:60 for 10-35 min; 0:100 for 35-50 min; 80:20 for 50-55 $\mathrm{min}$; and a holding time of $15 \mathrm{~min}$ at $30^{\circ} \mathrm{C}$. The flow rate was $1.0 \mathrm{~mL} \cdot \mathrm{min}^{-1}$. The chromatographic peaks were recorded at $\lambda=280 \mathrm{~nm}$. The qualitative and quantitative analyses of sterols are as described above.

\section{Analysis of ergothioneine}

The content of ergothioneine was analysed by the high-performance liquid chromatography; (RP-HPLC) method described previously (Zhou et al., 2014). A Hitachi HPLC system equipped with a type L-7100 pump was used for the analysis. The Purospher ${ }^{\circledR}$ RP$18 \mathrm{e}(4 \mathrm{~mm} \times 200 \mathrm{~mm}, 5 \mu \mathrm{m})$ column was maintained at $25{ }^{\circ} \mathrm{C}$, and the ultraviolet; (UV) detector was operated at $\lambda=257 \mathrm{~nm}$. A mixture of $1 \%$ methanol containing boric acid adjusted to $\mathrm{pH} 5.0$ was used as the liquid phase at a flow rate of $0.5 \mathrm{~mL} \cdot \mathrm{min}^{-1}$. The qualitative and quantitative analyses of ergothioneine is as described above.

\section{Analysis of lovastatin}

Lovastatin determination was carried out using the high-performance liquid chromatography; (RPHPLC) method described previously (Kała et al., 2020). The apparatus was equipped with a ultraviolet; (UV) detector $(\lambda=238 \mathrm{~nm})$, a column (Purospher ${ }^{\circledR}$ RP-18e, $14 \mathrm{~mm} \times 200 \mathrm{~mm}, 5 \mu \mathrm{m})$ and a lamp (L7100). All the measurements were performed using a previously prepared developing system (acetonitrile and $0.1 \%$ phosphoric acid at the ratio of $60: 40[\mathrm{v} / \mathrm{v}])$. The quantitative analysis of lovastatin was performed analogously to that for other organic compounds.

\section{Total phenol analysis}

Total polyphenol content was measured as gallic acid equivalents using the Folin-Ciocalteu method (Emmons et al., 1999). The Folin-Ciocalteu reagent containing molybdenum (VI) was added to the obtained extracts. The phenols in the extract reduce molybdenum (VI) to molybdenum (V). The compound formed in this reaction is blue with an absorption maximum at the wavelength of $745-750 \mathrm{~nm}$. The colour was measured using a Thermo Scientific Helios $\beta$ spectrophotometer. The higher the concentration of phenols was in the sample, the greater the degree of absorption.

\section{1,1-diphenyl-2-picrylhydrazyl (DPPH) analysis}

The antioxidant activity of the analysed samples was measured by a spectrophotometric method, namely the 1,1-diphenyl-2-picrylhydrazyl (DPPH) radical (SigmaAldrich) scavenging assay. Samples were weighted in four repetitions $(0.01 \mathrm{~g}$ each). Next, $5 \mathrm{~mL}$ of $0.1 \mathrm{mM}$ $\mathrm{DPPH}$ solution in $80 \%$ methanol was added to the weighted samples. The mixture was stirred for $1 \mathrm{~h}$ in a centrifuge (ELMI DOS-20L shaker) at $120 \mathrm{rpm}$ in darkness at room temperature. After that, solutions were filtered through laboratory filters. Absorbance was measured at $\lambda=517 \mathrm{~nm}$ with a Helios Beta UVVIS spectrophotometer (Thermo Fisher Scientific Inc., Waltham, MA, USA). The DPPH radical reduction was calculated using the formula AA $(\%)=((\mathrm{A} 0-\mathrm{A} 1) /$ $\mathrm{A} 0) \times 100$, where AA is the antioxidant activity (\%), 
A0 is the blank/zero sample absorbance and A1 is the absorbance of the examined concentration of tested material (Brand-Williams et al., 1995).

\section{Statistical analysis}

All results are presented as mean values of six independent replicates $\pm \mathrm{SD}$ in three repetitions. Statistically significant differences of the selected bioelements and secondary metabolites in the examined fruiting bodies of $A$. bisporus obtained from three cultivation flushes were analysed using one-way ANOVA with a post-hoc Tukey's test.

\section{RESULTS AND DISCUSSION}

\section{Bioelements}

Mushrooms, including the A. bisporus species, have a natural ability to bioaccumulate metals (including macroelements - $\mathrm{Ca}, \mathrm{Mg}, \mathrm{Na}$ and $\mathrm{K}$; and microelements $\mathrm{Cu}, \mathrm{Fe}$ and $\mathrm{Zn}$ ). This interesting feature can be used to obtain fruiting bodies with a specific qualitative and quantitative composition. In the present study, the composition of the growth medium (Figure 1) for the mushroom compost (A. bisporus) and the content of the abovementioned bioelements in fruiting bodies obtained from three breeding flushes were determined (Figure 2).

The analysis of the substrates (Figure 1) showed that the fresh substrate had the highest content of both macro- and microelements: $\mathrm{Ca}-1,082 \mathrm{mg} \cdot 100 \mathrm{~g}^{-1}$ d.w., $\mathrm{Mg}-1,091 \mathrm{mg} \cdot 100 \mathrm{~g}^{-1}$ d.w., $\mathrm{Na}-2,310 \mathrm{mg} \cdot 100 \mathrm{~g}^{-1}$ d.w., $\mathrm{K}-1,851 \mathrm{mg} \cdot 100 \mathrm{~g}^{-1}$ d.w., $\mathrm{Cu}-16.1 \mathrm{mg} \cdot 100 \mathrm{~g}^{-1}$ d.w., $\mathrm{Fe}-29.8 \mathrm{mg} \cdot 100 \mathrm{~g}^{-1}$ d.w. and $\mathrm{Zn}-41.1 \mathrm{mg} \cdot 100 \mathrm{~g}^{-1}$ d.w. The following elements showed the lowest content in the substrate left over from Flush III: Ca $-219 \mathrm{mg} \cdot 100 \mathrm{~g}^{-1}$ d.w., $\mathrm{Mg}-130.2 \mathrm{mg} \cdot 100 \mathrm{~g}^{-1}$ d.w., $\mathrm{Na}-381 \mathrm{mg} \cdot 100 \mathrm{~g}^{-1}$ d.w., $\mathrm{K}-368 \mathrm{mg} \cdot 100 \mathrm{~g}^{-1}$ d.w., $\mathrm{Cu}-1.6 \mathrm{mg} \cdot 100 \mathrm{~g}^{-1}$ d.w., $\mathrm{Fe}-2.9 \mathrm{mg} \cdot 100 \mathrm{~g}^{-1}$ d.w. and $\mathrm{Zn}-11.53 \mathrm{mg} \cdot 100 \mathrm{~g}^{-1}$ d.w. The decrease in the content of bioelements in the substrate with consecutive flushes was accompanied by an increase in their content in fruiting bodies. The highest concentrations of elements in most cases were observed in fruiting bodies collected after Flush I: Na $-727 \mathrm{mg} \cdot 100 \mathrm{~g}^{-1}$ d.w., $\mathrm{K}-521 \mathrm{mg} \cdot 100 \mathrm{~g}^{-1}$ d.w., $\mathrm{Cu}$ $-2.1 \mathrm{mg} \cdot 100 \mathrm{~g}^{-1}$ d.w., Fe $-3.51 \mathrm{mg} \cdot 100 \mathrm{~g}^{-1}$ d.w., and $\mathrm{Zn}-17.2 \mathrm{mg} \cdot 100 \mathrm{~g}^{-1}$ d.w.; the exceptions were $\mathrm{Ca}-$ $389 \mathrm{mg} \cdot 100 \mathrm{~g}^{-1}$ d.w. and $\mathrm{Mg}-167.5 \mathrm{mg} \cdot 100 \mathrm{~g}^{-1}$ d.w. - in this case, these values were higher in the fruiting bodies of the second flush. a)

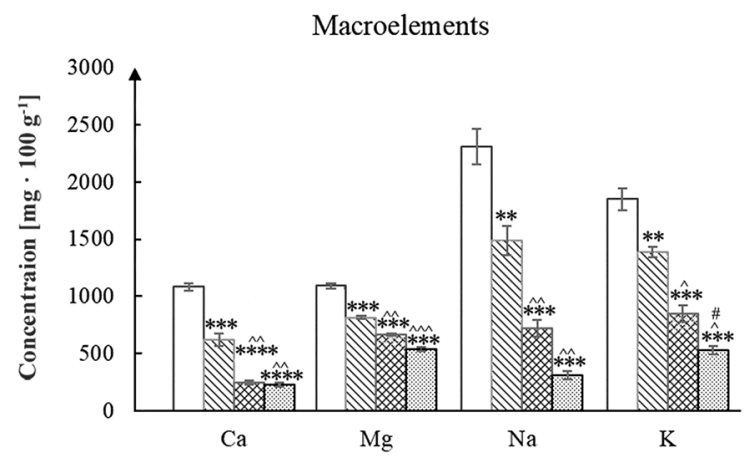

b)

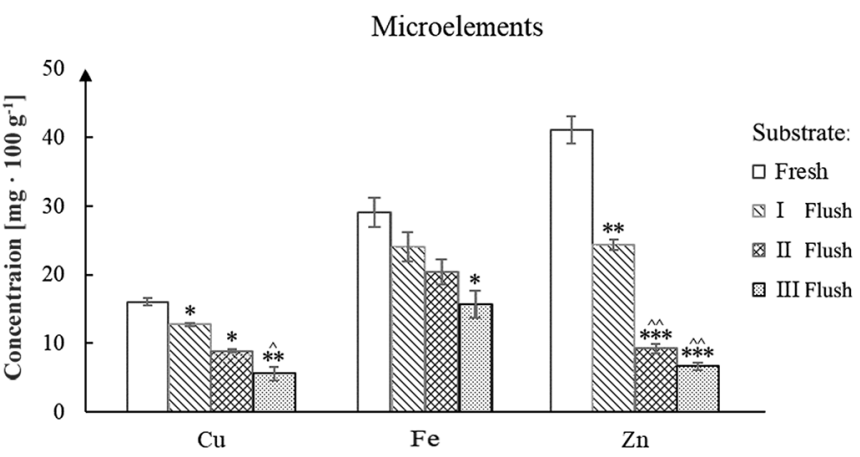

Figure 1. Concentration of (A) macroelements and (B) microelements in substrates $\left[\mathrm{mg} \cdot 100 \mathrm{~g}^{-1}\right.$ substrate] (one-way ANOVA with a post-hoc Tukey's test: ${ }^{*} p<0.05, * * p<0.01, * * * p<0.001, * * * * p<0.0001 v s$. Fresh Substrate Control; ${ }^{\wedge} p<0.05, \wedge \wedge p 0.01,{ }^{\wedge \wedge} p<0.001 v s$. Substrate from Flush I Control; $\# p<0.05 v s$. Substrate from Flush II Control).

a)

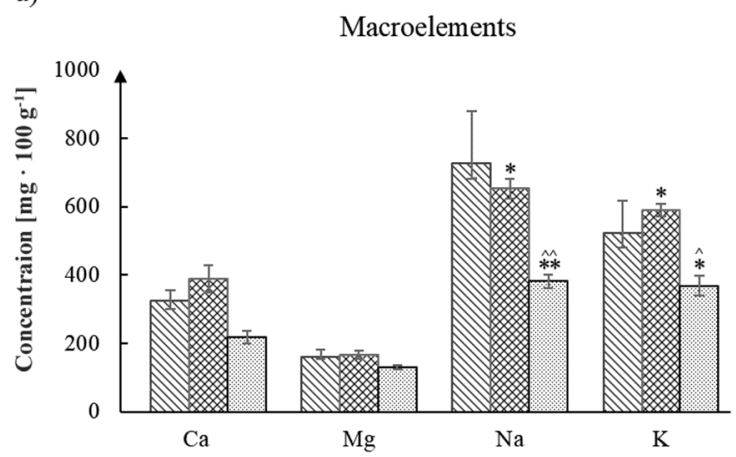

b)

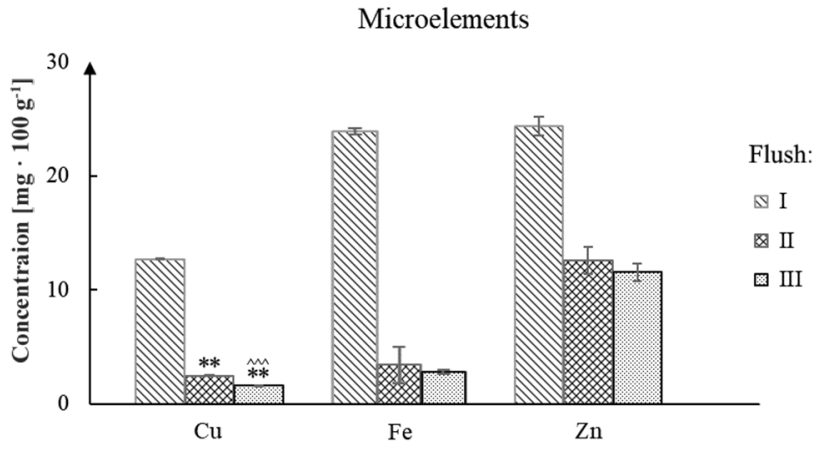

Figure 2. Concentration of (A) macroelements and (B) microelements in fruiting bodies of A. bisporus obtained from three cultivation flushes [mg $100 \mathrm{~g}^{-1}$ dry weight] (one-way ANOVA with a post-hoc Tukey's test: ${ }^{*} p<0.05$, ${ }^{* *} p<0.01$ vs. A. bisporus Flush I Control; ${ }^{\wedge} p<0.05, \wedge \wedge p 0.01$ vs. A. bisporus Flush II Control). 
To determine the optimal output of $A$. bisporus fruiting bodies in terms of the content of bioelements, the modified BCF was calculated, defined as the content of an element accumulated by mushroom fruiting bodies in relation to the concentration of this bioelement in the medium. The value of the BCF coefficient was calculated using equation:

$$
\begin{aligned}
\mathrm{BCF}= & \frac{\text { Concentration of the bioelement in the }}{\text { Concentration of the bioelement in the }} \\
& \text { solid medium }\left(\mathrm{mg} \cdot \mathrm{kg}^{-1}\right)
\end{aligned}
$$

The calculated values of BCF are presented in Figure 3. The amount of bioelements in fruiting bodies was compared to their content in the media left over from the harvesting of successive projections (column chart) and to their content in the starting media or fresh media (line graphs).

As shown by the analysis of the BCF coefficient, an opposite trend was observed in these two considered cases (ground after the crop has been harvested and fresh substrate). Comparison of the content of bioelements in fruiting bodies with their content in fresh medium showed the highest value of the BCF coefficient for the first flush. This is related to the highest availability of the elements in the starting material. A gradual increase in the $\mathrm{BCF}$ value was observed for each bioelement when its content determined in fruiting bodies collected from individual flushes was compared to that in the substrates after the next harvest. The increase in BCF in subsequent flushes was related to the mycelium growth and indicates that the natural mycelium overgrowth in the solid medium increases the ability to accumulate and transport bioelements to fruiting bodies. The increased adsorption surface resulted in an improved efficiency in the accumulation of elements by mycelium, followed by transportation to the newly formed fruiting bodies. The tendency to accumulate bioelements at different periods of growth enabled the substrate to become enriched in bioelements at certain time periods of cultivation in order to obtain fruiting bodies with a higher content of elements and thus a higher nutritional value in each of the obtained flushes. In the present experiment, the $\mathrm{BCF}$ coefficient value was the highest for $\mathrm{Cu}, \mathrm{Fe}$ and $\mathrm{Mg}$ for fruiting bodies collected from Flush II and for $\mathrm{Ca}, \mathrm{K}, \mathrm{Na}$ and $\mathrm{Zn}$ for fruiting bodies collected from Flush III. On the other hand, among the analysed macro- and microelements, the highest value of $\mathrm{BCF}$ was observed for $\mathrm{Zn}$ and the lowest for Fe. The results of this study showed that A. bisporus exhibited the highest efficiency in $\mathrm{Zn}$ accumulation and the lowest efficiency in Fe accumulation. Previous studies have shown that $A$. bisporus is a very good source of $\mathrm{Zn}$; this is vital information because this element is an important component of digestive enzymes, is necessary for protein synthesis and is involved in insulin storage, antidepressant activity and activation of more than 300 enzymes (Grzywacz et al., 2015). The determined Zn content in fruiting bodies obtained from individual flushes was as follows: Flush I - $17.2 \mathrm{mg} \cdot 100 \mathrm{~g}^{-1}$ d.w., Flush II - $12.6 \mathrm{mg} \cdot 100 \mathrm{~g}^{-1}$ d.w. and Flush III - $11.5 \mathrm{mg} \cdot 100 \mathrm{~g}^{-1}$ d.w. As shown, the content of $\mathrm{Zn}$ and other elements in fruiting bodies collected from successive flushes decreased, which is not favourable for the dietary values of the analysed species. The daily requirement for this element in a healthy adult depends on age and is approximately $15 \mathrm{mg}$ (Caballero et al., 2003). In other experiments, the amount of $\mathrm{Zn}$ released from fruiting bodies and biomass from in-vitro cultures of $A$. bisporus to a model digestive system was determined. A survey of literature data revealed that $\mathrm{Zn}$ is released from the fruiting bodies of $A$. bisporus into artificial digestive juices in small amounts in the order of approximately $2 \mathrm{mg} \cdot 100 \mathrm{~g}^{-1} \mathrm{~d}$.w. The total amount of $\mathrm{Zn}$ released from $A$. bisporus biomass obtained in vitro

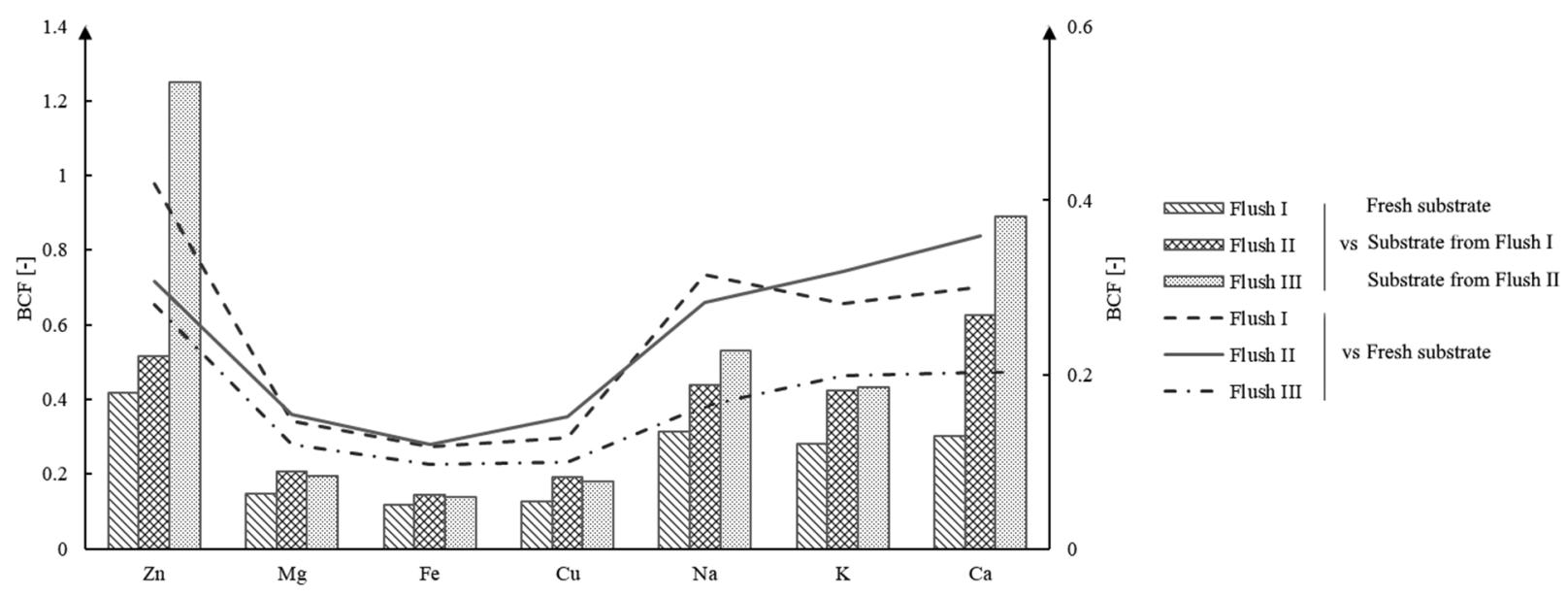

Figure 3. The value of the BCF coefficient for individual macro- and microelements calculated in relation to the fresh substrate (column chart) and to the substrates obtained after the set of projections (line charts). BCF, bioconcentration factor. 
was on average $10 \mathrm{mg} \cdot 100 \mathrm{~g}^{-1} \mathrm{~d} . \mathrm{w}$. The highest total concentration of this element released into artificial digestive juices was observed in the biomass of A. bisporus cultures obtained on the medium supplemented with $\mathrm{MgSO}_{4} \cdot 7 \mathrm{H}_{2} \mathrm{O}$ salt (up to $87 \mathrm{mg}$. $100 \mathrm{~g}^{-1}$ d.w.) (Krakowska et al., 2016). As confirmed in previous experiments and in the present study, the possibility of modifying the composition of the substrate in vitro can enable to cultivate fruiting bodies with a controlled enriched quantitative and qualitative composition are obtained in specific projections.

\section{Organic compounds}

The content of selected organic compounds, namely phenolic compounds (phenolic acids, flavonoids), total phenol content, indole compounds, phenylalanine, ergosterol, lovastatin and ergothioneine, was determined by the HPLC method in three A. bisporus flushes, and the second flush was found to contain the lowest level of these compounds (Table 1).

The levels of four phenolic compounds, namely gallic acid, $p$-hydroxybenzoic acid, rutoside and quercetin, were determined in $A$. bisporus flushes. The levels of phenolic compounds ranged from 0.01 (rutoside) to $18.20 \mathrm{mg} \cdot 100 \mathrm{~g}^{-1}$ d.w. (gallic acid). Flush I contained the highest amount of determined phenolic compounds. The amount of these compounds was the lowest in Flush II (Table 1). The amounts of phenolic compounds reported in fruiting bodies of $A$. bisporus by other authors ranged from $0.23 \mathrm{mg} \cdot 100 \mathrm{~g}^{-1} \mathrm{~d}$.w. (for $p$-coumaric acid) to $272 \mathrm{mg} \cdot 100 \mathrm{~g}^{-1} \mathrm{~d}$.w. (for myricetin) (Czapski, 2005).

Phenolic compounds exhibit antioxidant, antibacterial, antiviral, antifungal, anti-inflammatory and gastric-secretion stimulatory effects, as reported by in-vitro and in-vivo studies (Labus et al., 2011; Liu et al., 2013). In an Australian study, a positive correlation was observed between microbial inhibition and the total amount of phenolic compounds in ethanol extracts from fruiting bodies of $A$. bisporus (Ndungutse et al., 2015). The total amount of phenols was highest in Flush I and lowest in Flush II and ranged from $47.43 \mathrm{mg} \cdot \mathrm{g}^{-1} \mathrm{~d} . \mathrm{w}$. to $43.81 \mathrm{mg} \cdot \mathrm{g}^{-1} \mathrm{~d} . \mathrm{w}$. in these flushes, respectively.

The same tendency was observed for indole compounds; the highest amount was determined in flush I, moderate in flush III and lowest in $A$. bisporus flush II (Table 1). The highest amount of indole compounds was determined for L-tryptophan and 5-HTP from Flushes I and III. Indole compounds are important because of their anti-inflammatory, anticancer and antiaging activities; these compounds also regulate cell cycle and blood clotting (Muszyńska et al., 2016). The pharmacological profile of these compounds also includes antioxidant and antidepressant activities. The predominant indole compound was 5-HTP, which crosses the blood-brain barrier and is a direct precursor of serotonin and

Table 1. Content of organic compounds and total phenols and antioxidant activity (DPPH) of $A$. bisporus extracts from three flushes.

\begin{tabular}{|c|c|c|c|}
\hline Compounds/flush & $\mathrm{I}$ & II & III \\
\hline \multicolumn{4}{|c|}{ Phenolic compounds (mg $\cdot 100 \mathrm{~g}^{-1}$ d.w.) } \\
\hline Gallic acid & $18.20 \pm 0.40$ & $12.91 \pm 0.20^{* * * *}$ & $15.0 \pm 0.40^{* * * * \wedge \wedge}$ \\
\hline$p$-Hydroxybenzoic acid & $2.26 \pm 0.002$ & $1.37 \pm 0.003^{* * * *}$ & $1.84 \pm 0.002^{* * * * \wedge \wedge \wedge}$ \\
\hline Rutoside & $0.07 \pm 0.003$ & $0.12 \pm 0.004^{* * * *}$ & $0.01 \pm 0.001^{* * * * \wedge \wedge \wedge \wedge}$ \\
\hline Quercetin & $7.17 \pm 0.02$ & $5.11 \pm 0.002^{* * * *}$ & $5.18 \pm 0.05^{* * * *}$ \\
\hline Total phenols & $47.43 \pm 1.52$ & $43.81 \pm 0.93^{* *}$ & $45.51 \pm 3.7^{* * * \wedge}$ \\
\hline \multicolumn{4}{|c|}{ Indole compounds (mg $\cdot 100 \mathrm{~g}^{-1}$ d.w.) } \\
\hline L-Tryptophan & $221.71 \pm 0.9$ & $118.30 \pm 0.2^{* * * *}$ & $170.82 \pm 1.0^{* * * * * \wedge \wedge \wedge}$ \\
\hline 5-НТР & $213.99 \pm 5.71$ & $145.64 \pm 5.45^{* * * *}$ & $199.56 \pm 3.45^{* \wedge \wedge \wedge}$ \\
\hline Serotonin & $63.08 \pm 1.00$ & $36.42 \pm 1.77^{* * * *}$ & $70.08 \pm 4.19^{* \wedge \wedge \wedge}$ \\
\hline \multicolumn{4}{|l|}{ Sterols (mg $\cdot 100 \mathrm{~g}^{-1}$ d.w.) } \\
\hline Ergosterol & $64.32 \pm 0.08$ & $30.53 \pm 0.89^{* * * *}$ & $3.56 \pm 0.51^{* * * * \wedge \wedge \wedge \wedge}$ \\
\hline Ergosterol peroxide & $23.08 \pm 0.34$ & $17.71 \pm 0.04^{* * *}$ & $13.71 \pm 0.41^{* * * \wedge \wedge}$ \\
\hline Ergocalciferol & - & - & - \\
\hline \multicolumn{4}{|c|}{ Other compounds (mg $\cdot 100 \mathrm{~g}^{-1}$ d.w.) } \\
\hline Phenylalanine & $386.2 \pm 14.80$ & $254.1 \pm 9.41^{* * * *}$ & $300.2 \pm 11.71^{* * * \wedge \wedge}$ \\
\hline Lovastatin & $5.71 \pm 0.35$ & $1.69 \pm 0.13^{* * * *}$ & $3.47 \pm 0.32^{* * * \wedge \wedge}$ \\
\hline Ergothioneine & $10.88 \pm 0.98$ & $7.56 \pm 0.83$ & $14.74 \pm 3.92^{\wedge}$ \\
\hline DPPH (\%) & $89.41 \pm 0.90$ & $82.32 \pm 3.20$ & $76.71 \pm 1.40$ \\
\hline
\end{tabular}

$n=6$; one-way ANOVA with a post-hoc Tukey's test.

$* * p<0.01, * * * * p<0.0001$ vs. A. bisporus Flush I Control.

${ }^{\wedge} p<0.05, \wedge \wedge p<0.01,{ }^{\wedge \wedge} p<0.001,{ }^{\wedge \wedge \wedge} p<0.0001$ vs. A. bisporus Flush II Control - under limit detection.

DPPH, 1,1-diphenyl-2-picrylhydrazyl; 5-HTP, 5-hydroxy-L-tryptophan. 
melatonin, thus confirming the antidepressant activity of mushroom materials (Muszyńska et al., 2015b). A. bisporus is a recognised source of indole compounds (Muszyńska et al., 2016).

Phenylalanine was the dominant secondary metabolite in the present experiments, and its amount ranged from $386.2 \mathrm{mg} \cdot 100 \mathrm{~g}^{-1}$ d.w. (Flush I) to $300.2 \mathrm{mg} \cdot 100 \mathrm{~g}^{-1}$ d.w. (Flush III) and was the lowest in Flush II (254.1 mg $\cdot 100 \mathrm{~g}^{-1}$ d.w.). The high amount of phenylalanine, a precursor of indole compounds (L-tryptophan, 5-HTP and serotonin) and high amounts of these compounds could be responsible for the antidepressant effects of all $A$. bisporus cultivation flushes (Muszyńska et al., 2015b).

The amount of ergosterol determined in A. bisporus flushes ranged from $64.32 \mathrm{mg} \cdot 100 \mathrm{~g}^{-1}$ d.w. to $3.56 \mathrm{mg} \cdot 100 \mathrm{~g}^{-1}$ d.w. Ergosterol, present in fruiting bodies of edible mushrooms such as Imleria badia and $A$. bisporus, shows anti-inflammatory and antitumor activity (Ferreira et al., 2009). The ergosterol-enriched extracts of Lentinula edodes (order Agaricales) confirmed anti-inflammatory properties in a mice model. In C57B1/6 mice with mitogen (concanavalin A) induced hepatitis, supplementation with $L$. edodes extract enriched with vitamin D by UV-B radiation resulted in hepatoprotective activity. Changes in tissue histopathological images showed improvement in morphology of hepatocytes, while biochemical markers of liver damage such as plasma levels of aminotransferases and INF- $\gamma$ were decreased. Furthermore, an anti-inflammatory activity was proved through a synergistic effect of vitamin D and mushroom extract (Drori et al., 2016). Supplementation of powdered A. bisporus fruiting bodies enriched with vitamin $\mathrm{D}_{2}$ was found to contribute to a significant decrease in the level of high sensitivity C-reactive protein (hsCRP) protein, which is a biochemical marker of inflammation in humans (Stepien et al., 2013). Moreover, UV-B and UV-C radiation treatment during the cultivation process of edible mushrooms causes an increase in their fruiting bodies' vitamin $\mathrm{D}_{2}$ content (Drori et al., 2016). A. bisporus fruiting bodies are rich in ergosterol (approximately $61.5 \mathrm{mg} \cdot 100 \mathrm{~g}^{-1}$ d.w.) and ergocalciferol (Muszyńska et al., 2017).

Lovastatin, an active substance found in drugs called statins, used in the treatment of hypercholesterolaemia in the US and Europe, is one of the most significant active substances found in edible mushrooms. The mechanism of action of lovastatin is inhibition of 3-Hydroksy-3-metyloglutarylokoenzym A (HMG$\mathrm{CoA}$ ) reductase, which is one of enzymes involved in cholesterol synthesis pathway in the liver. The substance can be found in A. bisporus fruiting bodies (Kała et al., 2020). In the present study, the highest quantity (5.71 mg $\cdot 100 \mathrm{~g}^{-1}$ d.w.) of this secondary metabolite was determined in Flush I, while the lowest amount (1.69 $\mathrm{mg} \cdot 100 \mathrm{~g}^{-1}$ d.w.) was observed in Flush III, similar to other compounds.
Ergothioneine showed the same tendency as that observed for previously described organic compounds. The amount of ergothioneine in Flush II was $7.56 \mathrm{mg} \cdot 100 \mathrm{~g}^{-1}$ d.w. The highest content (14.74 mg $\cdot 100 \mathrm{~g}^{-1}$ d.w.) of this compound was obtained in Flush III. These data showed that $A$. bisporus is one of the best sources of this compound (Chen et al., 2012).

Ergothioneine is a water-soluble compound that can be synthesised by some mycobacteria and moulds, whereas it cannot be synthesised by animals; however, the latter can absorb the compound from food and store it in cells which are prone to oxidative stress, such as erythrocytes, eye lens and sperm. Ergothioneine compound showed the ability to reduce damage of tissue caused by irradiation, hypoxia (in particular, in transplanted organs), heart attack or brain stroke. It is a substrate for organic cation/carnitine transporter 1 (OCTN1). The transporter is associated with diseases caused by chronic inflammation such as Crohn's disease and rheumatoid arthritis. Furthermore, OCTN1 is expressed in hematopoietic cells which can proliferate and differentiate to erythroid cells. Apart from antioxidant activity, ergothioneine shows antimutagenic and chemo- and radioprotective effects (Chen et al., 2006).

The DPPH radical scavenging activity ranged from $89.41 \%$ in Flush I to $76.71 \%$ in Flush III. This tendency could be correlated with the decreasing amount of bioelements with antioxidant activity. Based on these results, Flush I shows the highest antidepressant activity (also containing the highest amount of antidepressant bioelement - zinc) (Szewczyk et al., 2019).

\section{CONCLUSIONS}

The fruiting bodies of $A$. bisporus, which is one of the most cultivated and consumed mushrooms worldwide, are a good source of many bioactive substances. The present study showed that the A. bisporus cultivation flushes differed in their content of bioelements and organic compounds. The first of the three examined $A$. bisporus cultivation flushes were the most valuable and rich in dietary and nutritional substance. Thus, in the present study, the first flush exhibited high pro-health and dietary value based on the content of bioelements and organic compounds and showed the highest level of antioxidant activity. To the best of our knowledge, the present study is the first to conduct such a complex analysis of these metabolites in $A$. bisporus cultivation flushes.

The next stage of this experiment will be the fortification of the substrate with the addition of salt solutions of inorganic/organic elements between the flushes to increase the concentration of the elements in the substrate and the use of increased mycelium adsorption surface resulting from its natural growth to obtain a product with higher content of dietary and prohealth substances. 


\section{ACKNOWLEDGEMENTS}

The authors gratefully acknowledge Marek Sakson and Paweł Gmitriuk for providing Agaricus bisporus sample materials from commercial cultivation.

\section{FUNDING}

The present study was carried out with the use of equipment co-financed by the Priority Research Area qLIFE under the programme "Excellence Initiative Research University" at the Jagiellonian University.

\section{AUTHOR CONTRIBUTIONS}

B.M. designed and directed the project. A.W., K.S-Z. A.K. and B.M. carried out the experiments. B.M., A.K. and A.W. wrote the manuscript. A.K. and J.L. collected the literature data. A.K. and J.L. prepared the graphical part of the manuscript. All authors discussed the results and contributed to the final manuscript.

\section{CONFLICT OF INTEREST}

The authors declare that no competing interests exist.

\section{REFERENCES}

Brand-Williams, W., Cuvelier, M. E., and Berset, C. (1995). Use of a free radical method to evaluate antioxidant activity. LWT - Food Science and Technology, 28, 25-30, doi: 10.1016/S00236438(95)80008-5.

Caballero, B., Trugo, L., and Finglas, P. (2003). Encyclopedia of food sciences and nutrition. Retrieved from https://agris.fao.org/agris-search/ search.do?recordID $=$ US201300082710

Chen, S., Oh, S.-R., Phung, S., Hur, G., Ye, J. J., Kwok, S. L., and Williams, D. (2006). Antiaromatase activity of phytochemicals in white button mushrooms (Agaricus bisporus). Cancer Research, 66(24), 12026-12034. doi: 10.1158/0008-5472. CAN-06-2206.

Chen, S.-Y., Ho, K.-J., Hsieh, Y.-J., WAng, L.-T., AND MaU, J.-L. (2012). Contents of lovastatin, g-aminobutyric acid and ergothioneine in mushroom fruiting bodies and mycelia. LWT - Food Science and Technology, 47, 274-278.

Czapski, J. (2005). Antioxidant activity and phenolic content in some strains of mushrooms (Agaricus bisporus). Vegetable Crops Research Bulletin, 62, 165-173.

Drori, A., Shabat, Y., Ben Ya'acov, A., Danay, O., Levanon, D., Zolotarov, L., And Ilan, Y. (2016). Extracts from Lentinula edodes (Shiitake) edible mushrooms enriched with vitamin d exert an antiinflammatory hepatoprotective effect. Journal of Medicinal Food, 19(4), 383-389, doi: 10.1089/ jmf.2015.0111.

Dubost, N. J., Ou, B., And Beelman, R. B. (2007). Quantification of polyphenols and ergothioneine in cultivated mushrooms and correlation to total antioxidant capacity. Food Chemistry, 105(2), 727 735, doi: 10.1016/j.foodchem.2007.01.030.

Emmons, C. L., Peterson, D. M., and Paul, G. L. (1999). Antioxidant capacity of oat (Avena sativa L.) extracts. 2. In vitro antioxidant activity and contents of phenolic and tocol antioxidants. Journal of Agricultural and Food Chemistry, 47(12), 4894-4898, doi: 10.1021/jf990530i.

Ferreira, I., Barros, L., AND Abreu, R. (2009). Antioxidants in wild mushrooms. Current Medicinal Chemistry, 16(12), 1543-1560, doi: 10.2174/092986709787909587.

Grzywacz, A., Gdula-Argasińska, J., Muszyńska, B., Tyszka-Czochara, M., Librowski, T., AND OpoKa, W. (2015). Metal responsive transcription factor 1 (MTF-1) regulates zinc dependent cellular processes at the molecular level. Acta Biochimica Polonica, 62(3), doi: 10.18388/abp.2015 1038.

Jurak, E., Patyshakuliyeva, A., De Vries, R. P., Gruppen, H., and Kabel, M. A. (2015). Compost grown Agaricus bisporus lacks the ability to degrade and consume highly substituted xylan fragments. PLoS ONE, 10(8), e0134169, doi: 10.1371/journal. pone.0134169.

KaŁa, K., Kryczyk-Poprawa, A., Rzewińska, A., And MuszyŃSKA, B. (2020). Fruiting bodies of selected edible mushrooms as a potential source of lovastatin. European Food Research and Technology, 246(4), 713-722, doi: 10.1007/s00217-020-03435-w.

Krakowska, A., Reczyński, W., And Muszyńska, B. (2016). Optimization of the liquid culture medium composition to obtain the mycelium of Agaricus bisporus rich in essential minerals. Biological Trace Element Research, 173(1), 231-240, doi: 10.1007/ s12011-016-0638-y.

Labus, K., Turek, A., Liesiene, J., And Bryjak, J. (2011). Efficient Agaricus bisporus tyrosinase immobilization on cellulose-based carriers. Biochemical Engineering Journal, 56(3), 232-240, doi: 10.1016/j.bej.2011.07.003.

LiU, J., JiA, L., KAN, J., AND Jin, C. H. (2013). In vitro and in vivo antioxidant activity of ethanolic extract of white button mushroom (Agaricus bisporus). Food and Chemical Toxicology, 51(1), 310-316, doi: 10.1016/j.fct.2012.10.014.

MuszyńSKa, B., Grzywacz-KisielewsKa, A., KaŁA, K., AND Gdula-ArgasińsKa, J. (2018). Antiinflammatory properties of edible mushrooms: A review. Food Chemistry, 243, 373-381, doi: 10.1016/j. foodchem.2017.09.149.

Muszyńska, B., KaŁa, K., Rojowski, J., Grzywacz, A., AND OpOKA, W. (2017). Composition and 
biological properties of Agaricus bisporus fruiting bodies - A review. Polish Journal of Food and Nutrition Sciences, 67(3), 173-181, doi: 10.1515/ pjfns-2016-0032.

Muszyńska, B., KaŁa, K., Sulkowska-Ziaja, K., Krakowska, A., and Opoka, W. (2016). Agaricus bisporus and its in vitro culture as a source of indole compounds released into artificial digestive juices. Food Chemistry, 199, 509-515, doi: 10.1016/j. foodchem.2015.12.041.

Muszyńska, B., Łojewski, M., RoJowski, J., OpoKA, W., SuŁkowska-Ziaja, K., and Ekiert, H. (2015b). Natural products of relevance in the prevention and supportive treatment of depression. Psychiatria Polska, 49(3), 435-453, doi: 10.12740/PP/29367.

Muszyńska, B., Krakowska, A., SuŁkowska-Ziaja, K., OpOKA, W., RECZYŃSKI, W., AND BAś, B. (2015a). In vitro cultures and fruiting bodies of culinarymedicinal Agaricus bisporus (white button mushroom) as a source of selected biologically-active elements. Journal of Food Science and Technology, 52(11), 7337-7344, doi: 10.1007/s13197-015-1830-3.

Ndungutse, V., Mereddy, R., and Sultanbawa, Y. (2015). Bioactive properties of mushroom (Agaricus bisporus) stipe extracts. Journal of Food Processing and Preservation, 39(6), 2225-2233, doi: 10.1111/ jfpp.12467.

Novaes, M. R. C. G., Valadares, F., Reis, M. C., Gonçalves, D. R., And Menezes, M. DA C. (2011). The effects of dietary supplementation with Agaricales mushrooms and other medicinal fungi on breast cancer: Evidence-based medicine. Clinics, 66, 21332139, doi: 10.1590/S1807-59322011001200021.

Rai, S. N., Mishra, D., Singh, P., Vamanu, E., And Singh, M. P. (2021). Therapeutic applications of mushrooms and their biomolecules along with a glimpse of in silico approach in neurodegenerative diseases. Biomedicine and Pharmacotherapy, 137, 111377, doi: 10.1016/j.biopha.2021.111377.

SPENCER, D. (1985). Mushroom, its history and importance. In P. Flegg, D. Spencer, and D. Wood (Eds), The biology and technology of the cultivated mushroom (pp. 1-8). Chichester, UK: John Wiley \& Sons Ltd.
Stepien, M., O’mahony, L., O'sullivan, A., Collier, J., Fraser, W. D., Gibney, M. J., And Brennan, L. (2013). Human and clinical nutrition: Effect of supplementation with vitamin $\mathrm{D}_{2}$-enhanced mushrooms on vitamin $\mathrm{d}$ status in healthy adults. Journal of Nutritional Science, 2, 1-9, doi: 10.1017/jns.2013.22.

Sulkowska-Ziaja, K., Szewczyk, A., Galanty, A., Gdula-Argasińska, J., And Muszyńska, B. (2018). Chemical composition and biological activity of extracts from fruiting bodies and mycelial cultures of Fomitopsis betulina. Molecular Biology Reports, 45(6), 2535-2544, doi: 10.1007/s11033-018-4420-4.

Szewczyk, B., Pochwat, B., Muszyńska, B., Opoka, W., Krakowska, A., Rafalo-UlińsKa, A., AnD NowAK, G. (2019). Antidepressant-like activity of hyperforin and changes in BDNF and zinc levels in mice exposed to chronic unpredictable mild stress. Behavioural Brain Research, 372, 112045, doi: 10.1016/j.bbr.2019.112045.

WŁodarczyk, A., Krakowska, A., Sulkowska-Ziaja, K., Suchanek, M., ZięBA, P., Opoka, W., And MuszyŃSKA, B. (2020). Pleurotus spp. mycelia enriched in magnesium and zinc salts as a potential functional food. Molecules, 26(1), 162, doi: 10.3390/ molecules26010162.

Yuan, J.-P., Kuang, H.-C., Wang, J.-H., and Liu, X. (2008). Evaluation of ergosterol and its esters in the pileus, gill, and stipe tissues of agaric fungi and their relative changes in the comminuted fungal tissues. Applied Microbiology and Biotechnology, 80(3), 459-465, doi: 10.1007/s00253-008-1589-9.

Zhang, L., Liu, Z., Sun, Y., Wang, X., And Li, L. (2020). Combined antioxidant and sensory effects of active chitosan/zein film containing $\alpha$-tocopherol on Agaricus bisporus. Food Packaging and Shelf Life, 24, 100470, doi: 10.1016/j.fpsl.2020.100470.

Zhou, T., Liu, Q., Jiang, W., And Chen, N. (2014). A new strategy for quantitative analysis of ergothioneine in fermentation broth by high-performance liquid chromatography; (RP-HPLC). Lecture Notes in Electrical Engineering, 249 LNEE (Vol. 1), 313-321, doi: 10.1007/978-3-642-37916-1_32.

Received: October 29, 2021; accepted: January 13, 2022 